\title{
Nedsatt syn hos barn og unge i Norge
}

\begin{abstract}
BAKGRUNN Grunnet sviktende tilmelding og dårlig datasikkerhet ble Blindekartoteket nedlagt i 1995. Etter den tid har det ikke eksistert noen synsregistrering i Norge. Alle de andre nordiske landene har registre for barn og unge med nedsatt syn. Hensikten med den aktuelle studien var å kartlegge synsvansker og årsaker til synsnedsettelse hos barn og unge samt vurdere behovet for et øyemedisinsk register.
\end{abstract}

MATERIALE OG METODE Via de fylkesvise synspedagogiske sentrene ble det i perioden 2005-10 samlet inn data om barn og unge under 20 år med nedsatt syn ( $n=628)$. Dette ble gjort som en punktprevalensstudie per 1.1.2004. Synsfunksjon, øyemedisinsk diagnose, systemisk diagnose og tilleggsfunksjonsvansker ble registrert.

RESULTATER Av barn og unge med nedsatt syn var om lag to tredeler svaksynte og en tredel blinde. De tre største diagnosegruppene var nevrooftalmologiske sykdommer (37\%), retinale sykdommer (19\%) og tilstander som rammer øyeeplet generelt (14\%). Forekomsten av tilleggsfunksjonsvansker var høy, $53 \%$, som oftest motoriske problemer eller kognitive vansker.

FORTOLKNING Resultatene av studien stemmer godt overens med resultatene fra tilsvarende undersøkelser i de andre nordiske land. Vår studie viser at de synspedagogiske registrene ikke er gode nok når det gjelder medisinske data, og den understreker nødvendigheten av et øyemedisinsk register over barn og unge med nedsatt syn.

Å ha nedsatt syn medfører store utfordringer på mange livsområder - $\mathrm{i}$ skolegang, $\mathrm{i}$ arbeid og fritid, i familierelasjoner og i samfunnet for øvrig. Hos barn får nedsatt syn ekstra store konsekvenser fordi synssansen er så fundamental i den tidlige utviklingen på mange ulike områder, det gjelder eksempelvis motorikk og sosial tilpasning. For at barn med nedsatt syn skal få en optimal utvikling, er det av største viktighet at de får god oppfølging, både fra den medisinske profesjon og fra det spesialpedagogiske og synspedagogiske fagmiljøet.

For samfunnet er det viktig å ha kunnskap om forekomst og omfang av ulike funksjonsvansker, slik at nødvendig hjelp og ressurser kan stilles til rådighet og fordeles best mulig. Her i landet var vi relativt tidlig ute med å fremskaffe data om nedsatt syn. Øyelege Johan C. Holst publiserte tidlig i 1950årene et banebrytende arbeid om forekomsten av blindhet i Norge, med detaljert informasjon om medisinske diagnoser (1). Et annet viktig norsk arbeid på dette feltet er Magnus Odlands medisinske og sosialmedisinske studie av blinde og svaksynte i Hordaland i 1970-årene (2). I arbeidet rapporterte Odland særskilt om forekomsten av blindhet og svaksynthet hos barn $(<20$ år).

Johan C. Holst var drivkraften bak opprettelsen av Det norske blindekartotek, et nasjonalt register over personer med nedsatt syn, med meldeplikt for alle øyeleger. Blindekartoteket ble opprettet allerede i 1968 og var således et av de tidligste helseregistre i landet. På grunn av økte krav til datasikkerhet og personvern samt avtagende tilmelding til registeret ble det nedlagt i 1995. Etter dette har det ikke eksistert noen nasjonal oversikt over personer med nedsatt syn i Norge.

\section{Synspedagogisk tilbud}

Barn med nedsatt syn er ikke bare avhengig av god øyemedisinsk utredning, behandling og oppfølging, like viktig er habiliterings- og rehabiliteringsarbeidet, som i stor grad utføres av synspedagoger (3). Opplæringsloven og barnehageloven slår fast at det skal tas hensyn til barnets funksjonsnivå og at det skal gis tilpasset opplæring. For barn med synshemning betyr det at de har krav på fagpersoner som kan bistå lærerne og førskolelærerne med synsfaglig kompetanse. Det er den pedagogisk-psykologiske tjenesten (PPT) i kommunen som $i$ utgangspunktet er pålagt dette ansvaret. De færreste kommuner har egne synspedagoger, derfor er de avhengig av å kunne hente inn denne kompetansen utenfra.

Den offentlige synspedagogtjenesten har lenge vært i støpeskjeen, men er nå organisert i Statped-systemet, den statlige spesialpedagogiske tjenesten, som foruten syn også dekker områdene døvblindhet, hørsel, språk/tale, ervervet hjerneskade og sammensatte lærevansker. Statped er inndelt i fire regioner (Sørøst, Vest, Midt, Nord) som hver betjener sine respektive kommuner og fylkeskommuner, i form av individbaserte og systembaserte tjenester.

\section{Synsregistre i de øvrige nordiske land}

I samtlige av de andre landene i Norden finnes det $\mathrm{i}$ dag et nasjonalt register for personer

\author{
Olav H. Haugen \\ olav.haugen@helse-bergen.no \\ Cecilie Bredrup \\ Eyvind Rødahl \\ $\emptyset$ yeavdelingen \\ Haukeland universitetssykehus \\ og \\ Klinisk institutt 1 \\ Det medisinsk-odontologiske fakultet \\ Universitetet i Bergen
}

> Se lederartikkel side 978

ab Engelsk oversettelse på www.tidsskriftet.no

\section{HOVEDBUDSKAP}

Etter nedleggelsen av Blindekartoteket i 1995 har Norge, som eneste nordiske land, ingen medisinsk registrering av barn og unge med nedsatt syn

Hyppigste årsak til nedsatt syn hos barn og unge i Norge er nevrooftalmologiske sykdommer, fulgt av retinale sykdommer og tilstander som rammer øyeeplet generelt

Mer enn halvparten av barn og unge med nedsatt syn har tilleggsfunksjonsvansker

Det er behov for et norsk øyemedisinsk register over barn og unge med nedsatt syn 
med nedsatt syn. I Danmark har det vært et slikt register siden 1930-årene, men kun for barn ( $0-17$ år). Det er meldeplikt til registeret, og registrering er en forutsetning for å motta synsrehabilitering (4). Finland har hatt meldepliktig registrering av alle med nedsatt syn, uansett alder, siden midten av 1980årene (5). I Sverige fikk man etablert et synsregister i midten av 1960-årene, men virksomheten lå nede i mange år før registeret ble reetablert i 1990. Det omfatter i dag bare barn (0-19 år). Det islandske registeret omfatter hele aldersspekteret og har vært i drift fra slutten av 1980-årene (6).

Rundt 1990 ble det etablert en prosjektgruppe av nordiske øyeleger, NORDSYN. Gruppen ønsket å samle data omkring barn med nedsatt syn i de nordiske land. Arbeidet var basert på de nasjonale registrene, med unntak av Sverige, siden registeret der da hadde ligget nede i mange år. Prosjektet resulterte i flere artikler, som omhandlet prevalensdata, etiologiske faktorer, diagnoser og kjønnsfordeling (7-10).

I Sverige førte reetableringen av et synsregister for barn til et doktorgradsarbeid (11), med delpublikasjoner etter samme mønster som NORDSYN-studien (12-14). I denne avhandlingen ble det funnet en aldersspesifikk prevalens av nedsatt syn på 11 per 10000 (0-19 år) og en aldersspesifikk prevalens av blindhet på 29 per 100000 (0-15 år).

\section{Situasjonen i Norge}

Situasjonen per i dag er den at det eksisterer aktive og oppdaterte registre over barn med nedsatt syn $i$ alle de nordiske land, med unntak av Norge. Etter nedleggelsen av Blindekartoteket i 1995 ble det oppnevnt en arbeidsgruppe som skulle utrede en mulig videreføring av virksomheten. Rapporten fra denne arbeidsgruppen forelå i 1997. Den konkluderte med at det burde etableres et sentralt, landsdekkende register over personer med nedsatt syn, i første omgang begrenset til barn og unge opptil 20 år.

I høringsrunden fikk rapporten bred tilslutning. Imidlertid ble saken lagt til side (brev fra Statens helsetilsyn i oktober 1998) med begrunnelsen at man ventet på helseregisterloven. Etter at denne loven ble vedtatt i 2002, ble registersaken tatt opp igjen, både av øyeleger som arbeider spesielt med barn, øyelegeforeningen (Norsk oftalmologisk forening) og Blindeforbundet. Så langt har det imidlertid ikke ført til opprettelse av et synsregister.

Ut fra denne situasjonen ble det i 2004 startet et forskningsprosjekt. Hensikten var å samle inn data om barn og unge med nedsatt syn, med hovedvekt på grad av synssvekkelse, diagnosegrupper, etiologi og forekomst av tilleggsvansker. I tillegg ønsket man at prosjektet kunne fungere som en pilotstudie for etablering av et register.

Tabell 1 Klassifisering av nedsatt syn i henhold til ICD-10 (WHO)

\begin{tabular}{lll}
\hline Gruppe & Visus $(\mathrm{x})^{1}$ & Synsfelt \\
Moderat nedsatt syn, kategori 1 & $0,1 \leq x<0,33$ & \\
Alvorlig nedsatt syn, kategori 2 & $0,05 \leq x<0,1$ & \\
Blindhet, kategori 3 & $0,02 \leq x<0,05 \quad \begin{array}{l}\text { Synsfelt } \leq 10^{\circ} \text { radius omkring fiksa- } \\
\text { sjonspunktet luavhengig av visus) }\end{array}$ \\
Blindhet, kategori 4 & Lyssans $\leq x<0,02$ & \\
Blindhet, kategori 5 & Ingen lyssans & \\
Kategori 9 & Ubestemt & \\
\hline
\end{tabular}

${ }^{1}$ Beste korrigerte visus på det beste øye

Hensikten med denne artikkelen er å presentere data fra undersøkelsen, belyse noen av de spesielle forholdene som gjør seg gjeldende for pasientgruppen samt peke på viktigheten og nødvendigheten av et medisinsk register over barn og unge med nedsatt syn.

\section{Materiale og metode}

Alle personer som har nedsatt syn i henhold til WHOs ICD-10-kriterier (15) (tab 1) og faller inn under opplæringsloven, har krav på synspedagogisk bistand. Synspedagogtjenesten har fra 1996 hatt konsesjon til å føre register over sine brukere. På bakgrunn av dette valgte man i prosjektet å søke samarbeid med synspedagogsentrene. Med samtykke fra brukere/foreldre innhenter synspedagogene også øyemedisinske opplysninger fra pasientens øyelege eller øyeavdeling.

Kartleggingen ble gjennomført som en punktprevalensstudie per 1.1.2004 (sammenfallende med oppstart av prosjektet) hos registrerte brukere under 20 år ved synspedagogtjenesten, som på den tiden var organisert med ett senter i hvert fylke. Av personvernhensyn ble invitasjonsbrevet til pasientene/ foreldrene sendt ut av det enkelte synspedagogiske senter på vegne av forskningsprosjektet, sammen med samtykkeerklæringen, som foreldrene skulle returnere til prosjektledelsen. Deretter ble registeropplysningene fra synspedagogsentrene om dem som hadde gitt samtykke gjort tilgjengelig for prosjektet.

Datainnsamlingen skjedde ved at prosjektmedlemmer reiste til hvert enkelt synspedagogiske senter, manuelt gikk gjennom registerjournalene og la inn de aktuelle variablene $i$ en database: kjønn, oftalmologisk hoved- og bidiagnose, systemisk hoved- og bidiagnose, korrigert visus på beste øye/binokulært, synsfelt og tilleggsvansker. I mange journaler var det synsfunksjonsdata fra flere ulike undersøkelsestidspunkter. Man valgte da å bruke data fra den undersøkelsen som lå nærmest i tid til 1.1.2004.

Mottatte samtykkeerklæringer ga tilgang til 845 registerjournaler til barn og unge under 20 år, og det ble innhentet data fra disse ved de synspedagogiske sentrene i perioden 2005-10. I 23 av tilfellene var journalopplysningene om synsfunksjon så mangelfulle eller uklare at de ble ekskludert fra den videre analysen.

Av de resterende 822 pasientene hadde 269 $(32,7 \%)$ per definisjon ikke nedsatt syn (korrigert visus på det beste øyet $\geq 0,33$ og ingen alvorlig synsfeltsinnskrenkning). 75 av denne gruppen $(8,9 \%)$ hadde visus 0,33 . Fordi man $i$ en del tidligere studier (bl.a. Odlands studie i Hordaland) (2) har regnet den sistnevnte kategori som nedsatt syn, har vi valgt å gjøre det samme i den videre presentasjonen, til tross for at WHO definerer nedsatt syn som visus $<0,33$. Materialet omfatter derfor 628 personer (346 gutter) med visus $\leq 0,33$.

Diagnosene ble registrert med ICD-10kode, både oftalmologisk hoveddiagnose og systemisk hoveddiagnose. Etter mønster fra NORDSYN-studien ble diagnosene også gruppert etter anatomisk lokalisering: tilstander lokalisert til øyet som helhet, medfødte tilstander i fremre segment, medfødte mis-

Tabell 2 Synsfunksjon hos 628 norske barn og unge < 20 år med nedsatt syn, klassifisert i henhold til WHO-kategorier

\begin{tabular}{|c|c|c|}
\hline Gruppe & Antall & $(\%)$ \\
\hline Visus $=0,33$ & 75 & $(11,9)$ \\
\hline $\begin{array}{l}\text { Moderat nedsatt syn, } \\
\text { kategori } 1\end{array}$ & 267 & $(42,5)$ \\
\hline $\begin{array}{l}\text { Alvorlig nedsatt syn, } \\
\text { kategori } 2\end{array}$ & 71 & $(11,3)$ \\
\hline Blindhet, kategori 3 & 106 & $(16,9)$ \\
\hline Blindhet, kategori 4 & 44 & $(7,0)$ \\
\hline Blindhet, kategori 5 & 47 & $(7,5)$ \\
\hline Kategori 9 & 18 & $(2,9)$ \\
\hline Totalt & 628 & $(100)$ \\
\hline
\end{tabular}


Tabell 3 Fordeling på oftalmologisk diagnosegruppe hos 628 barn og unge < 20 år med nedsatt syn

\begin{tabular}{|c|c|c|c|}
\hline Gruppe & Eksempel & Antall & $(\%)$ \\
\hline Tilstander lokalisert til øyet som helhet & Albinisme, eksessiv myopi & 87 & $(13,9)$ \\
\hline Medfødte tilstander fremre segment & Kongenitt katarakt, aniridi & 63 & $(10,0)$ \\
\hline Medfødte tilstander bakre segment & Hypoplasi av synsnerve, kolobom & 56 & $(8,9)$ \\
\hline Medfødte dysfunksjoner & Kongenitt nystagmus & 25 & $(4,0)$ \\
\hline Retinale sykdommer & $\begin{array}{l}\text { Retinitis pigmentosa, retinopati } \\
\text { hos premature }\end{array}$ & 120 & $(19,1)$ \\
\hline Nevrooftalmologiske sykdommer & $\begin{array}{l}\text { Cerebral synshemning, atrofi } \\
\text { av n. opticus }\end{array}$ & 234 & $(37,3)$ \\
\hline Diverse & Retinoblastom, kronisk uveitt & 25 & $(4,0)$ \\
\hline Usikker & & 18 & $(2,9)$ \\
\hline Totalt & & 628 & $(100)$ \\
\hline
\end{tabular}

Tabell 4 Fordeling på systemisk hoveddiagnose (ICD-10-gruppe) hos 628 barn og unge < 20 år med nedsatt syn

\begin{tabular}{|c|c|c|c|c|}
\hline \multirow[b]{2}{*}{ Gruppe (ICD-10) } & \multicolumn{2}{|c|}{ Totalmaterialet } & \multicolumn{2}{|c|}{$\begin{array}{l}\text { Nevrooftalmologiske } \\
\text { sykdommer }\end{array}$} \\
\hline & Antall & $(\%)$ & Antall & $(\%)$ \\
\hline $\mathrm{C}+\mathrm{D}$ Svulster & 22 & $(3,5)$ & 18 & $(7,7)$ \\
\hline E Metabolske forstyrrelser & 100 & $(15,9)$ & 7 & $(3,0)$ \\
\hline G Sykdommer i nervesystemet & 50 & $(8,0)$ & 44 & $(18,8)$ \\
\hline H Sykdommer i øyet & 71 & $(11,3)$ & 5 & $(2,1)$ \\
\hline I Følgetilstand etter hjerneblødning/hjerneslag & 5 & $(0,8)$ & 5 & $(2,1)$ \\
\hline P Tilstander som oppstår i perinatalperioden & 93 & $(14,8)$ & 60 & $(25,7)$ \\
\hline Q Medfødte misdannelser og kromosomavvik & 216 & $(34,4)$ & 62 & $(26,5)$ \\
\hline Andre/ukjent & 71 & $(11,3)$ & 33 & $(14,1)$ \\
\hline Totalt & 628 & $(100)$ & 234 & $(100)$ \\
\hline
\end{tabular}

dannelser i bakre segment, medfødte dysfunksjoner, retinale sykdommer, nevrooftalmologiske sykdommer og diverse tilstander.

På samme måte som i NORDSYN-studien ble følgende tilleggsfunksjonsvansker registrert: motoriske vansker (cerebral parese o.l.), kognitive vansker, nedsatt hørsel og epilepsi.

Studien er godkjent av regional komité for medisinsk og helsefaglig forskningsetikk Vest (nr. 116.03) og Norsk samfunnsvitenskapelig datatjeneste (nr. 10118).

\section{Resultater}

Synsfunksjon

I tabell 2 vises fordelingen av pasientene på de forskjellige grader av synssvekkelse. Av dem som etter definisjonen hadde nedsatt syn $(\mathrm{n}=628)$, var $413(66 \%)$ svaksynte (WHO-kategori 1-2) og 197 (31\%) blinde (WHO-kategori 3-5). Av de førstnevnte var et stort flertall, $83 \%$, moderat svaksynt (kategori 1).

Det forelå synsfeltsdata for 229 av de 628 inkluderte pasientene. Av disse hadde 132 dokumentert synsfeltsinnskrenkning, hvorav 17 med hemianopsi.

\section{Diagnose}

Fordeling på diagnosegruppe er presentert $\mathrm{i}$ tabell 3. De tre største diagnosegruppene var nevrooftalmologiske sykdommer $(\mathrm{n}=234$, $37,3 \%)$, retinale sykdommer $(n=120,19,1 \%)$ og tilstander som affiserer bulbus generelt $(\mathrm{n}=87,13,9 \%)$.
I gruppen nevrooftalmologiske sykdommer dominerte cerebral synshemning ( $81 \%)$ og atrofi av synsnerven (11\%), mens majoriteten av retinale sykdommer var arvelige netthinnedystrofier $(70 \%)$ og prematuritetsretinopati $(22 \%)$. Tabell 4 viser systemisk hoveddiagnose etter ICD-10-inndeling både for totalmaterialet og for den største oftalmologiske diagnosegruppen, nevrooftalmologiske sykdommer.

\section{Tilleggsvansker}

Totalt hadde 334 pasienter (53\%) minst én tilleggsvanske. De hyppigste slike problemer var motoriske vansker $(n=260,41 \%)$ og kognitive vansker $(\mathrm{n}=241,38 \%)$. Nedsatt hørsel var registrert hos 46 personer. De dominerende diagnosegruppene her var malformasjoner i bakre segment (f.eks. CHARGEsyndrom), retinale sykdommer og nevrooftalmologiske sykdommer. Epilepsi fantes hos 141 pasienter $(22 \%)$.

\section{Nevrooftalmologiske sykdommer}

Siden nevrooftalmologiske sykdommer var den klart største diagnosegruppen, ønsket vi å studere denne pasientgruppen nærmere. Den dominerende diagnosen var cerebral synshemning. Cerebral synssvekkelse defineres som regel ut fra følgende kriterier: strukturelt normal øyeundersøkelse, nedsatt synsfunksjon og påvist skade i bakre del av det visuelle system, det vil si bak chiasma opticum.

Sammenliknet med totalmaterialet var det i gruppen nevrooftalmologiske sykdommer en høyere andel blinde i forhold til svaksynte (andel blinde $46 \%$ versus $31 \%$ i totalmaterialet). I denne gruppen var det også vesentlig høyere forekomst av tilleggsvansker $-85 \%$ hadde minst én tilleggsvanske, $74 \%$ hadde to eller flere.

\section{Diskusjon}

Vår kartleggingsstudie viser at av norske barn som er registrert med nedsatt syn, var det $66 \%$ svaksynte (hos oss definert som visus 0,33 pluss WHO-kategori 1 og 2) og $31 \%$ blinde (WHO-kategori 3, 4 eller 5). Denne fordelingen mellom svaksynthet og blindhet samsvarer godt med fordelingen $\mathrm{i}$ den tilsvarende svenske studien fra 1990årene (12) og i NORDSYN-studien (7).

Det er i seg selv et interessant funn at nesten en tredel av de registrerte barna hadde visus $>0,33$ og således etter WHOs definisjon ikke har nedsatt syn. Dette kan bety at den synspedagogiske tjenesten ikke ensidig vektlegger visus som henvisningskriterium, men vurderer pasientens totale situasjon. I så fall anser vi dette for en god vurdering, siden man vet at en del barn med sammensatte vansker har synsproblemer som ikke nødvendigvis går utover visus, men i større grad rammer visuokognitive funksjoner. Våre 
data er ikke detaljerte nok til å si noe sikkert om dette er årsaken til det store antall barn med visus $>0,33$.

I de fleste studier av nedsatt syn hos barn er det en overvekt av gutter, slik også i vårt materiale. I NORDSYN-studien fant man en gutt-jente-ratio på 1,39 (7). I vår studie var denne ratioen $346 / 282=1,22$, i praksis lik ratioen på 1,20 i Blohmé \& Tornqvists studie fra Sverige (12).

Fra vår studie kan man peke på to hovedfunn. Det ene er at nevrooftalmologiske sykdommer, og spesielt cerebral synsnedsettelse, dominerer diagnosebildet. Tilsvarende funn ble gjort av NORDSYN-gruppen (9) og Blohmé \& Tornqvist i Sverige (14). Etiologisk er dette en heterogen gruppe - en del har en kjent hjerneskade fra perinatalperioden (bl.a. fødselsasfyksi og prematuritet), mens andre har genetisk betingede tilstander.

Det er nylig publisert studier der man ved helgenomsekvensering har kunnet verifisere genetisk årsak hos en stor andel av barn med cerebral synsnedsettelse og kognitive vansker (16). Dette er diagnostikk som i økende grad tas i bruk i vanlig klinisk utredning og som vil kunne gi en spesifikk diagnose hos flere av disse barna i fremtiden.

Det andre hovedfunnet er at mer enn halvparten av barna med nedsatt syn har tilleggsvansker, særlig motoriske problemer (cerebral parese) og kognitive vansker. Dette funnet samsvarer godt med den svenske studien, hvor man fant at $60 \%$ av alle barn med nedsatt syn hadde tilleggsvansker (13). Høyest forekomst av tilleggsvansker fant vi i gruppen med nevrooftalmologiske sykdommer, $85 \%$, noe som stemmer godt med funnene i den svenske studien, $88 \%$ (14).

Dette forholdet betyr at øyehelsetjenesten til barn med nedsatt syn i mange tilfeller må skje $\mathrm{i}$ et tverrfaglig samarbeid med barnelege, synspedagog, psykolog, nevropsyko$\log$, fysioterapeut og sosionom. Dessuten er et nært samarbeid med pasientforeninger og Norges Blindeforbund avgjørende for et optimalt resultat.

En spesiell gruppe det er viktig å være oppmerksom på, er de som har kombinerte syns- og hørselsvansker. Døvblindhet er definert som et eget fagområde innen Statped-systemet og omfatter alle som har kombinerte syns- og hørselsvansker. I vårt materiale utgjorde dette 46 pasienter $(7,3 \%)$.

Vår studie har noen åpenbare svakheter. Både utsending av invitasjonsbrev, purring, mottak av samtykke samt organiseringen og gjennomføringen av datainnsamlingen ble av ulike grunner langt mer tidkrevende enn først antatt, og studien har strukket seg over svært mange år. Likedan har gjennomgang av databasen med kvalitetssikring av dataene tatt atskillig mer tid enn forventet.

Fordi vi måtte rekruttere pasientene til denne studien via synspedagogtjenesten, og fordi vi var avhengig av skriftlig samtykke, er pasientmaterialet i studien ufullstendig og kan være selektert. Dette gjør at dataene må tolkes med forsiktighet $\mathrm{i}$ en epidemiologisk sammenheng. De tilgjengelige medisinske dataene er av varierende kvalitet. Likevel gir materialet et bilde av gruppen barn med nedsatt syn som følges i det synspedagogiske systemet.

Likhetstrekkene mellom våre data, NORDSYN-studien og Blohmé \& Tornqvists data tyder på at fordelingen mellom de ulike diagnostiske grupper samt fordelingen mellom svaksynthet og blindhet er noenlunde den samme i Norge som i de andre nordiske land.

Dersom vi legger til grunn de svenske aldersspesifikke prevalensdataene fra 1990årene (12), skulle vi ha omtrent 1450 blinde og svaksynte barn og unge her i landet. Ut fra en nyere studie fra England kan mye tyde på at mens andelen voksne med nedsatt syn avtar, er andelen barn med slike vansker økende (17). Man antar at årsakene til dette er ulike, men at økt overlevelse av små premature samt økende innvandring er to medvirkende forhold. Fordi vi ikke har noe norsk register, vet vi ikke om tilsvarende endringer gjør seg gjeldende $i$ vårt land.

$\mathrm{Vi}$ erfarte under registreringsarbeidet at de arkiverte medisinske opplysninger i det synspedagogiske registeret ikke kan fungere som et fullgodt register for øyemedisinske opplysninger, noe man heller ikke kan forvente. Siden avslutningen av datainnsamlingen er synspedagogtjenesten dessuten blitt omorganisert, som nevnt innledningsvis.

Statped-systemet skal heretter kun forholde seg til kommunene og ikke til spesialisthelsetjenesten. Det betyr et beklagelig byråkratisk hinder i det viktige samarbeidet mellom øyeleger og synspedagoger, noe som gjør det enda mer nødvendig å etablere et eget øyemedisinsk register for barn og unge med nedsatt syn.

\section{Konklusjon}

Vår studie tyder på at forekomsten av nedsatt syn hos barn og unge, fordelingen mellom svaksynte og blinde og fordelingen mellom ulike medisinske diagnosegrupper er relativt lik det man har funnet ved tilsvarende studier i de andre nordiske land. Per i dag registreres norske barn og unge med nedsatt syn kun av den synspedagogiske tjenesten, og dette registeret er ikke designet for å være et medisinsk register.

Norge er eneste land i Norden som ikke har et øyemedisinsk register, og det anbefales at et slikt opprettes snarlig. Dette vil blant annet kunne gi verdifull kunnskap om årsaker til synsnedsettelse hos barn og unge, muligheten til å fange opp endringer i sykdomspanoramaet hos barn og unge med nedsatt syn, bedre mulighet for optimal tverrfaglig behandling og oppfølging/habilitering/rehabilitering samt økt mulighet for forskning på dette feltet.

Registeret, som med fordel kan gjøres nettbasert, bør inneholde data om alder ved sykdomsdebut, kjønn, ulike aspekter ved synsfunksjonen (visus, synsfelt), øyemedisinsk og systemisk diagnose samt opplysninger om bidiagnoser og tilleggsvansker. Registeret bør være oppfølgende, med datainnsamling for eksempel hvert femte år, da en del øyesykdommer hos barn er progredierende. Det er vårt håp at opprettelsen av et slikt register kan skje innen overskuelig fremtid.

Vi takker de synspedagogiske sentrene i Norge for samarbeid og velvilje ved utsending av invitasjonsbrev samt for tilrettelegging ved datainnsamlingen. Prosjektet har fått økonomisk støtte fra Norges Blindeforbund. Foruten forfatterne har optiker Lars Helge Glomnes og sykepleier Else Ramsli deltatt i registrering av data ved de synspedagogiske sentrene. Vi vil også takke synspedagog Petter Dørum, Statped Vest, for gjennomlesing av manuskriptet og verdifulle kommentarer.

\section{Olav H. Haugen (f. 1955)}

er spesialist i øyesykdommer, professor og seksjonsoverlege ved Seksjon for pediatrisk oftalmologi og strabisme.

Forfatter har fylt ut ICMJE-skjemaet og oppgir ingen interessekonflikter.

\section{Cecilie Bredrup (f. 1973)}

er spesialist i øyesykdommer og forsker. Hun har spesialkompetanse innen pediatrisk oftalmologi og arvelige øyesykdommer.

Forfatter har fylt ut ICMJE-skjemaet og oppgir ingen interessekonflikter.

\section{Eyvind Rødahl (f. 1957)}

er spesialist i øyesykdommer og professor. Han har spesialkompetanse innen arvelige øyesykdommer og sykdommer i orbita.

Forfatter har fylt ut ICMJE-skjemaet og oppgir ingen interessekonflikter.

\footnotetext{
Litteratur

1. Holst JC. The occurrence of blindness in Norway. Am J Ophthalmol 1952; 35: 1153-66.

2. Odland M. Svaksyn og blindhet i Bergen og Horda land. En medisinsk og sosialmedisinsk undersøkelse. Doktoravhandling. Bergen: Institutt for oftalmologi, Universitetet i Bergen, 1976.

3. Hoyt CS, Jan JE. How to help the visually disabled child and family. I: Hoyt CS, Taylor D, red. Pediatric ophthalmology and strabismus, 4. utg. Edinburgh: Elsevier, 2013: 619-23

4. Kennedy Centret. Nationalt forsknings- og rådgivningscenter for genetic, synshandicap og mental retardering. www.kennedy.dk/default.aspx?id=173 (16.11.2015).

5. Finnish Federation of the Visually Impaired (FFVI). www.nkl.fi/7/english (16.11.2015). 
6. The National Institute for the Blind. Visually Impaired and Deafblind. http://midstod.is/english/ (16.11.2015).

7. Riise R, Flage T, Hansen E et al. Visual impairment in Nordic children. I. Nordic registers and prevalence data. Acta Ophthalmol (Copenh) 1992; 70: $145-54$.

8. Rosenberg T, Flage T, Hansen E et al. Visual impairment in Nordic children. II. Aetiological factors. Acta Ophthalmol (Copenh) 1992; 70: 155-64.

9. Hansen E, Flage T, Rosenberg T et al. Visual impairment in Nordic children. III. Diagnoses. Acta Ophthalmol (Copenh) 1992; 70: 597-604.

10. Riise R, Flage T, Hansen E et al. Visual impairment in Nordic children. IV. Sex distribution. Acta Ophthalmol (Copenh) 1992; 70: 605-9.

11. Blohmé J. On visual impairment in Swedish children. Doktoravhandling. Lund: Lund University Publications, 2000.

12. Blohmé J, Tornqvist K. Visual impairment in Swedish children. I. Register and prevalence data. Acta Ophthalmol Scand 1997; 75: 194-8.

13. Blohmé J, Tornqvist K. Visual impairment in Swedish children. II. Etiological factors. Acta Ophthalmol Scand 1997: 75: 199-205.

14. Blohmé J, Tornqvist K. Visual impairment in Swedish children. III. Diagnoses. Acta Ophthalmol Scand 1997; 75: 681-7.
15. ICD-10. International Statistical Classification of Diseases and Related Health Problems. 10. utgave. Genève: World Health Organization, 2010 16. Bosch DG, Boonstra FN, de Leeuw N et al. Novel genetic causes for cerebral visual impairment. Eur J Hum Genet 2016; 24: 660-5.

17. Mitry D, Bunce C, Wormald R et al. Childhood visual impairment in England: a rising trend. Arch Dis Child 2013; 98: 378-80.

Mottatt 19.11.2015, første revisjon innsendt 13.4. 2016, godkjent 2.5.2016. Redaktør: Tor Rosness. 